\title{
Verbal Abuse, Physical Assault, and Harassment in Pediatric Medical Settings: A Nationwide Survey in Japan
}

\author{
Rie Wakimizu1 $^{*}$, Hinako Kuwahara ${ }^{2}$ \\ ${ }^{1}$ Department of Child Health and Developmental Nursing, Faculty of Medicine, University of Tsukuba, Ibaraki, Japan \\ ${ }^{2}$ Department of Nursing, Toranomon Hospital, Tokyo, Japan \\ Email: ^riewaki@md.tsukuba.ac.jp
}

How to cite this paper: Wakimizu, R. and Kuwahara, H. (2022) Verbal Abuse, Physical Assault, and Harassment in Pediatric Medical Settings: A Nationwide Survey in Japan. Health, 14, 177-193.

https://doi.org/10.4236/health.2022.142013

Received: January 7, 2022

Accepted: January 27, 2022

Published: January 30, 2022

Copyright $\odot 2022$ by author(s) and Scientific Research Publishing Inc. This work is licensed under the Creative Commons Attribution International License (CC BY 4.0).

http://creativecommons.org/licenses/by/4.0/

\begin{abstract}
Background: Verbal abuse, physical assault, and harassment of pediatric healthcare workers by patients and their families have become increasingly serious. These incidents lead to various problems, including the deterioration of staff members' mental health and employee turnover. Methods: This study was conducted as the first Japanese nationwide survey to assess the abuse perpetrated by patients and families and experienced by medical staff in pediatric medical settings in 2018, countermeasures employed, and staff member evaluations of the countermeasures. Results: Responses from 526 facilities were received, clinics accounted for $79.8 \%$ of these facilities; $88.1 \%$ of the respondents were females. Further, $10.5 \%$ of the facility staff reported having experienced verbal abuse, violence, or harassment from patients or family members. Of 1103 cases of victimizations, there were 719, 136, and 248 cases of verbal abuse, violence, and harassment, respectively. Manuals and guidelines had been created and training and drill performances were conducted as countermeasures in $10.7 \%$ and $9.0 \%$ of facilities, respectively; $7.3 \%$ of staff members felt that the countermeasures were effective, corresponding to $45.6 \%$ of the affected staff. Conclusion: The findings suggest the necessity of thoroughly familiarizing staff with existing facility countermeasures as well as introducing new countermeasures such as victimization simulations.
\end{abstract}

\section{Keywords}

Verbal Abuse, Physical Assault, Harassment, Pediatric Medical Setting, Countermeasures

\section{Introduction}

A survey of university hospitals conducted in Japan found that $44.3 \%$ of staff 
members had experienced some form of abuse in the hospital within the past year, including verbal abuse and physical assault [1]. Experiences of verbal abuse committed by patients and their families have a significant impact on work and can lead to reduced turnover [2]; however, many staff members who have experienced such violence choose to endure it and continue to work without reporting the abuse, but they may start feeling anxious about their daily tasks [1] [3]. Overseas pediatric medical settings (wards, outpatient departments, and emergency departments) have also reported high rates of violence perpetrated by the families of children [4] [5] and that most staff members are subjected to instances of verbal abuse and physical assault [6] [7] [8].

Many people who have grown up in parallel with the shift from extended to nuclear families, with decreasing numbers of siblings and friends due to declining birthrates and weakening kinship bonds and relationships, may find it difficult to interact with people of diverse values, ideas, behaviors, and cultures. As a result, there are many families that make unreasonable demands and many parents who use verbal abuse and violence as an outlet for accumulated stress [9].

\section{Objective}

This study aimed to clarify the extent of verbal abuse, violence, and harassment exhibited by patients and their families and experienced by staff members in pediatric medical facilities in 2018. Further, the impact of these incidents on the subsequent work of the staff and the countermeasures implemented by managers and staff to address the violence was investigated.

\section{Materials and Methods}

\subsection{Study Design}

The study design was a mixed-methods approach.

\subsection{Survey Period}

The survey period was February to December 2018.

\subsection{Data Collection}

Data were collected from a total of 642 facilities. Facilities included regular members of the Japanese Association of Comprehensive Medical Care Facilities for Children; regular members of the National Council of Child and Adolescent Psychiatric Care Facilities; base hospitals for pediatric cancer, emergency centers, medical care and education centers; core facilities; and designated facilities among training facilities for perinatal specialists approved by the Japanese Society of Perinatology and Neonatology. Additionally, 2467 facilities to which members of the Japanese Society of Outpatient Pediatrics belonged were contacted as well.

The survey targeted medical professionals and related personnel (including 
doctors, nurses, midwives, technicians, pharmacists, administrative staff, and social workers).

The following recruiting method was used for this study. Letters were sent to the managers of each facility asking for their cooperation in the study. If the facility managers agreed to cooperate, they were asked to choose between answering a physical questionnaire or entering answers on a website maintained for the purposes of the study. If respondents chose to answer the physical questionnaire, questionnaires and return envelopes for all staff members were sent to the managers at a later date. If respondents chose to answer through the website, the relevant URL was shared with the facility manager, and responding staff members were instructed to navigate through the website entry gate from the URL individually. The data collected through questionnaire returns and website entries were compiled on a password-protected PC managed by the study's principal investigator.

\subsection{Data Analysis}

The total number of instances of verbal abuse, physical assault, and harassment experienced by staff members in pediatric medical facilities in 2018, most severe experience of each type of abuse, impact of the experience on the respondent's work, and the countermeasures implemented by the facility and staff members were tabulated. Based on the similarity of descriptions, labels were created to represent common meanings. Both quantitative and qualitative analyses were reviewed and revised repeatedly by the research assistant and the researcher.

\subsection{Ethical Consideration}

The study was approved by the Ethics Committee of the Society of Ambulatory and General Pediatrics of Japan and the Medical Ethics Committee of the Faculty of Medicine, University of Tsukuba (No. 1238).

\section{Results}

The questionnaire was sent to 2328 facilities (excluding duplicate facilities), and 525 facilities returned the questionnaires (response rate: 22.55\%). A total of 3610 data points were collected, including 29 data points collected by survey responses made via the website.

\subsection{Characteristics of the Target Facilities and Respondents (Table 1)}

Of the target facilities, $79.8 \%$ were clinics and $76.6 \%$ were outpatient facilities with zero beds. In terms of departmental specialization (multiple answers allowed), although pediatrics departments accounted for the largest number (482), a wide range of other specialties, including dermatology, otolaryngology, and urology, were also reported.

In terms of respondent demographics, $88.1 \%$ were female and the most common age group comprised those aged 41 - 50 years (32.5\%). The most common 
Table 1. Characteristics of target facilities and respondents.

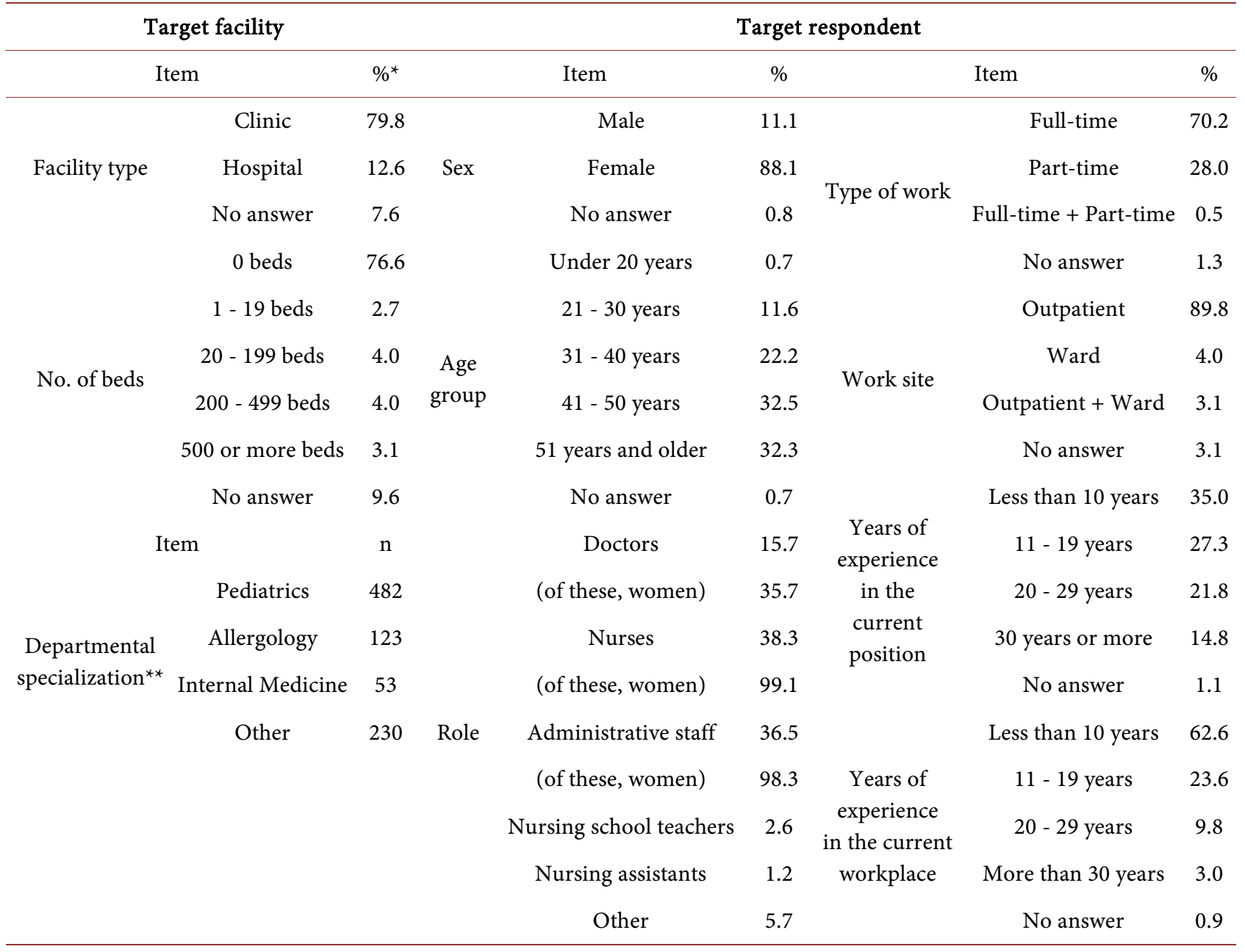

${ }^{\star}$ Rounded to the first decimal place. ${ }^{*}$ Multiple answers allowed (with duplicates).

facility staff roles were nurses (including midwives), administrative staff, and doctors, in that order; other roles included pharmacists, psychologists, and technicians. Among the top three roles (doctors, nurses, and administrative staff), the percentages of women were $35.7 \%, 99.1 \%$, and $98.3 \%$, respectively. Of the respondents, $70.2 \%$ worked full-time and $89.8 \%$ worked in outpatient clinics. The majority of respondents $(35.0 \%)$ had 10 years or less experience in their current roles; $62.6 \%$ had 10 years or less experience at their current workplace.

\subsection{Staff Member Experiences of Violence and Other Forms of Victimization (Table 2) and Actual Incidences of Verbal Abuse, Violence, and Harassment (Tables 3-5)}

A total of 1103 cases of verbal abuse, violence, and harassment, comprising 719 cases of verbal abuse, 136 cases of violence, and 248 cases of harassment, were reported in 2018, of which 18 cases were reported to the police and legal counsel was sought in response to eight cases. Some form of victimization was experienced by $10.5 \%$ of staff members in $2018 ; 17.8 \%$ of men and $9.8 \%$ of women 
had experienced victimization. Table 2 provides details concerning the victimization experiences for the most-reported three roles: doctors, nurses, and administrative staff. Tables 3-5 present characteristics of the offenders, the details of the offenses, the causes of the offenses, and the impact on the responding staff member's work, based on the respondents' recollections of their most severe experiences in 2018. It is necessary to note that the total number of cases, involving 719 cases of verbal abuse, 136 cases of violence, and 248 cases of harassment that comprised the total number of cases of each type of incident experienced by the respondent in 2018, does not match the total number of cases for each type of incident shown in the Tables; the Tables present the number of recollections concerning the respondents' most severe incident experiences in 2018.

Table 2. Incident victimization experience of doctors, nurses, and administrative staff.

\begin{tabular}{|c|c|c|}
\hline Role & Victimization experience & $\% *$ \\
\hline \multirow{4}{*}{ Doctors } & Yes & 18.0 \\
\hline & (of these, women) & 32.4 \\
\hline & No & 80.9 \\
\hline & No answer & 1.1 \\
\hline \multirow{4}{*}{ Nurses } & Yes & 9.5 \\
\hline & (of these, women) & 98.5 \\
\hline & No & 89.6 \\
\hline & No answer & 0.9 \\
\hline \multirow{4}{*}{ Administrative staff } & Yes & 9.3 \\
\hline & (of these, women) & 96.1 \\
\hline & No & 89.4 \\
\hline & No answer & 1.2 \\
\hline
\end{tabular}

${ }^{*}$ Rounded to the first decimal place.

Table 3. Details, causes, and impacts of actual verbal abuse incidents $(\mathrm{N}=403)$.

\begin{tabular}{|c|c|c|c|c|c|}
\hline & Item & $\mathrm{n}$ & & Item & $\mathbf{n}$ \\
\hline \multirow{6}{*}{ Offender } & Patient & 59 & \multirow{6}{*}{$\begin{array}{l}\text { Details of verbal abuse } \\
\text { (duplicates included) }\end{array}$} & Insulting statements & 162 \\
\hline & Father & 153 & & Disparaging statements & 81 \\
\hline & Mother & 154 & & Words such as "idiot" and "stupid" & 76 \\
\hline & Grandfather & 15 & & Dissatisfaction and complaints & 34 \\
\hline & Grandmother & 12 & & Intimidating statements & 28 \\
\hline & Other & 10 & & Threatening statements & 18 \\
\hline \multirow{2}{*}{$\begin{array}{l}\text { Offender's } \\
\text { sex }\end{array}$} & Male & 208 & & Other & 53 \\
\hline & Female & 195 & $\begin{array}{l}\text { Cause of verbal abuse } \\
\text { (duplicates included) }\end{array}$ & $\begin{array}{l}\text { Medical treatment or staff response that is not in } \\
\text { accordance with the patient's/family's wishes }\end{array}$ & 156 \\
\hline
\end{tabular}




\section{Continued}

\begin{tabular}{|c|c|c|c|c|c|}
\hline \multirow{12}{*}{$\begin{array}{l}\text { Offender's } \\
\text { age group } \\
\text { (in years) }\end{array}$} & $0-9$ years & 27 & & Long waiting time & 130 \\
\hline & $10-19$ & 11 & & Disease that the patient is suffering from & 37 \\
\hline & $20-29$ & 58 & & Insufficient explanation of test results and treatment plan & 37 \\
\hline & $30-39$ & 146 & & Hospital environment & 22 \\
\hline & $40-49$ & 84 & & Medical-fee related & 19 \\
\hline & $50-59$ & 31 & & Unknown & 19 \\
\hline & $60-69$ & 26 & & Other & 56 \\
\hline & \multirow[t]{5}{*}{$\geq 70$} & \multirow[t]{5}{*}{20} & \multirow{5}{*}{$\begin{array}{c}\text { Impact on work } \\
\text { (duplicates included) }\end{array}$} & None in particular & 308 \\
\hline & & & & Worsening of mental-health symptoms & 95 \\
\hline & & & & Interference with work & 53 \\
\hline & & & & Establishment of post-incident measures & 21 \\
\hline & & & & Other & 10 \\
\hline
\end{tabular}

Table 4. Details, causes, and impacts of actual incidents of physical violence $(\mathrm{N}=56)$.

\begin{tabular}{|c|c|c|c|c|c|}
\hline & Item & $\mathbf{n}$ & & Item & $\mathbf{n}$ \\
\hline & Patient & 47 & & Kicked & 33 \\
\hline & Father & 3 & & Hit & 30 \\
\hline & Mother & 2 & & Bitten & 19 \\
\hline Otfender & Grandfather & 4 & $\begin{array}{l}\text { Details of physical } \\
\text { violence }\end{array}$ & Pinched & 14 \\
\hline & Grandmother & 0 & (duplicates included) & Punched & 12 \\
\hline & Other & 0 & & Pushed & 10 \\
\hline Offender's & Male & 47 & & Objects thrown & 9 \\
\hline $\operatorname{sex}$ & Female & 9 & & Other & 7 \\
\hline & $0-9$ years & 41 & & $\begin{array}{l}\text { Medical treatment or staff response that is not in } \\
\text { line with the patient's/family's wishes }\end{array}$ & 25 \\
\hline & $10-19$ & 5 & & Personality, characteristics, and character & 12 \\
\hline Offender's & $20-29$ & 1 & & Length of waiting time & 5 \\
\hline age group & $30-39$ & 3 & Cause of physical violence & Hospital environment & 2 \\
\hline (in years) & $40-49$ & 2 & & Insufficient explanation of test results and treatment plan & 1 \\
\hline & $50-59$ & 0 & & Medical-fee related & 1 \\
\hline & $60-69$ & 2 & & Unknown & 6 \\
\hline & $\geq 70$ & 2 & & Other & 11 \\
\hline & & & & None in particular & 44 \\
\hline & & & & Deterioration of physical symptoms & 8 \\
\hline & & & $\begin{array}{c}\text { Impact on work } \\
\text { (duplicates included) }\end{array}$ & Worsening of mental-health symptoms & 5 \\
\hline & & & & Interference with work & 4 \\
\hline & & & & Other & 2 \\
\hline
\end{tabular}


Table 5. Details, causes, and impacts of the actual state of incidents of harassment $(\mathrm{N}=148)$.

\begin{tabular}{|c|c|c|c|c|c|}
\hline & Item & $\mathbf{n}$ & & Item & $\mathbf{n}$ \\
\hline & Patient & 6 & & Behaved agitatedly and belligerently & 74 \\
\hline & Father & 41 & & Glared menacingly & 49 \\
\hline & Mother & 79 & & Acted in an intimidating manner & 31 \\
\hline Offender & Grandfather & 6 & $\begin{array}{l}\text { Details of harassment } \\
\text { (duplicates included) }\end{array}$ & Acted in a threatening manner & 10 \\
\hline & Grandmother & 12 & & Demanded money & 3 \\
\hline & Other & 4 & & Demanded that staff kneel apologetically on the ground & 3 \\
\hline Offender's & Male & 50 & & Other & 28 \\
\hline $\operatorname{sex}$ & Female & 98 & & Long waiting time & 51 \\
\hline & 0 - 9 years & 3 & & $\begin{array}{l}\text { Medical treatment or staff response that is not in line } \\
\text { with the patient's/family's wishes }\end{array}$ & 40 \\
\hline & $10-19$ & 2 & & Insufficient explanation of test results or treatment plan & 17 \\
\hline Offender's & $20-29$ & 24 & Cause of harassment & Disease that the patient is suffering from & 10 \\
\hline age group & $30-39$ & 56 & & Medical-fee related & 7 \\
\hline (in years) & $40-49$ & 35 & & Hospital environment & 4 \\
\hline & $50-59$ & 12 & & Unknown & 14 \\
\hline & $60-69$ & 9 & & Other & 22 \\
\hline & $\geq 70$ & 7 & & None in particular & 114 \\
\hline & & & & Worsening of mental-health symptoms & 34 \\
\hline & & & $\begin{array}{c}\text { Impact on work } \\
\text { (duplicates included) }\end{array}$ & Interference with work & 16 \\
\hline & & & & Establishment of post-incident measures & 4 \\
\hline & & & & Other & 10 \\
\hline
\end{tabular}

\subsubsection{Verbal Abuse}

A total of 719 instances of verbal abuse were reported. Of these, the analysis of 403 responses detailing the most severe experiences of harm from verbal abuse in 2018 demonstrated that most verbal abusers were "fathers" and "mothers", and most were aged 30 - 39 years. Many of the rude comments were "insulting words", such as, "Are you really a nurse (I don't think so...)". There were also reports of "threatening statements", such as, "If anything happens to this child, I will sue you..." and "I will show everyone how this hospital does things on SNS!" The most common provocations of verbal abuse were "medical treatment or staff response that was not in line with the wishes of the patient/family", including requests for compliance with facility rules, hasty transfers, and "long waiting times". Another reason cited was "crowded parking lots around the facility, making it difficult to park". The effects of verbal abuse on staff members' work included "worsening of psychological symptoms", such as depressed mood, decreased motivation to work, and flashbacks, and "interference with work", including interruption of reception-area work, poor empathy in the hospital, and work errors due to distraction. However, some staff members were 
able to devise and implement post-harassment measures, including changing their responsibilities, creating documents to prevent a recurrence, and conducting harassment training (Table 3).

\subsubsection{Physical Assault}

There were a total of 136 cases of physical assault reported, with six cases resulting in damage to facility equipment. Analysis of the 56 responses detailing the most severe experiences of harm (physical abuse) in 2018 revealed that the perpetrators of violence were mostly the patients themselves, predominantly comprising male children. The most common examples of violence were staff being "kicked" and "hit". Being "choked" and "spit on" were also mentioned. The most common reasons cited for violence were "medical treatment or staff responses that were not in line with the patient's/family's wishes" and "personalities and characteristics (of the perpetrators)", while other reasons included "the doctor explained the situation only to the parents (without telling the patient)", and "the family was in an intoxicated state". The effects of physical assault on work included "worsening of physical symptoms", such as fractures, bruises, and pain in the injured area, "worsening of mental symptoms", such as fear of providing medical assistance to a violent patient or fear of reprisal at a later date, and "disruption of work duties", such as interruption of work due to the need to interact with police (Table 4).

\subsubsection{Harassment}

There were 248 reports of harassment. An analysis of 56 responses detailing the most severe experiences of harassment in 2018 showed that most harassers were mothers, mainly comprising women aged 30 - 39 years. The most common harassment involved an "agitated and belligerent attitude", while the category "other" included ignoring relevant professional advice, forcing an apology, lingering around, repeatedly failing to see a doctor after making an appointment under a false name, and slander and defamation through online posts. The most common justification for harassment was a "long waiting time", while the category "other" included warnings from staff to follow hospital rules, the facility's appointment system, and the patient's belief that they had been demoted in the order of appointments. In terms of the impact of harassment on work, "worsening of psychological symptoms", including depressed mood, "disruption of work", including interruption of reception-area work, and "establishment of postincident measures", including measures to avoid becoming disturbed by repeatedly occurring incidents were all reported (Table 5).

\subsection{Facility Countermeasures against Harm and Staff Awareness}

The most common facility security measure that staff members were aware of in response to incidents of verbal abuse, assault, and harassment was found to be "installation of emergency call buttons and emergency phones". Support efforts for affected staff members included "multiple responses to the patient/family" as 
the most common, followed by "interviews and counseling" and "cessation of contact with the patient/family". Responses indicated that $10.7 \%$ of the staff members were aware of the existence of response manuals and guidelines at the facility, 9.0\% were aware of the existence of training and drills, and $29.0 \%$ were aware of systems for sharing or reporting after an incident had occurred. In terms of effectiveness, $7.3 \%$ of the staff felt that facility measures were effective; $45.6 \%$ of staff members who were affected reported that the measures were effective, while $54.3 \%$ reported the measures were ineffective. Approximately $26.5 \%$ of respondents felt that they were able to share their feelings at work. When those who felt that they could not share their feelings were asked why, the most common response was that "it was difficult to both report the incident and express their emotions regarding their experience" $(24.8 \%)$, followed by "they did not know whom to ask" (22.9\%); $20.0 \%$ felt that their point of view would not be understood. "Other" reasons included being too busy (Table 6).

\section{Discussion}

This study investigated incidents of verbal abuse, physical assault, and harassment by patients and their families in pediatric healthcare settings, the countermeasures implemented by facilities and staff, and the impact of victimization on staff members and their work. Discussion follows on the measures implemented by facility managers and staff against violence and other harassment based on the actual situations and current conditions that were revealed by the study's survey responses and analysis.

\subsection{Verbal Abuse, Physical Assault, and Harassment Incidents}

Although the study results revealed that $10.5 \%$ of staff members working in pediatric healthcare settings had experienced violence or other forms of victimization, this figure was not as high as the $33 \%-89 \%$ of employees who reported experiencing victimization within the past year in previous studies overseas [3] [4] [5] and in Japan [10] [11] [12] [13]. The current study found that the majority of incidents of "physical assault" were perpetrated by the patients themselves (most of whom were male children, through attempts to resist treatment), while "verbal abuse" and "harassment" were committed more often by parents and extended family members of patients rather than by the patients themselves (involving predominately expressions of stress and frustration). The majority of the facilities represented in this study were pediatric departments.

In this study, the percentage of staff members with victimization experience was higher among men and doctors $(17.8 \%$ of men vs $9.5 \%$ of women; $18.0 \%$ of doctors vs $9.5 \%$ of nurses and $9.3 \%$ of administrative staff). When comparing the percentage experiences of victimization by sex and occupation, those of "women" and "nurses" stood out with higher percentages reported in previous Japanese studies [10] [11] [12] [13] [14], whereas a recent non-Japanese report found that the percentage of those experiencing victimization was significantly 
Table 6. Hospital measures to handle incidents and staff's perceptions of such measures.

\begin{tabular}{|c|c|c|c|c|c|}
\hline & Item & $\mathbf{n}$ & & Item & $\% *$ \\
\hline & $\begin{array}{l}\text { Installation of emergency call } \\
\text { buttons and emergency telephones }\end{array}$ & 625 & & I am aware of it & 10.7 \\
\hline & Crime prevention video recordings & 600 & $\begin{array}{l}\text { Existence of } \\
\text { response manuals }\end{array}$ & I am not aware of it & 76.8 \\
\hline & $\begin{array}{l}\text { Sharing of information on patients and families } \\
\text { who have perpetrated violence in the past }\end{array}$ & 560 & and guidelines & Cannot say either way & 0.0 \\
\hline Security & Displaying posters & 289 & & No answer & 12.5 \\
\hline measures & Hiring security guards & 232 & & I am aware of it & 9.0 \\
\hline in place ${ }^{\star *}$ & Participation in training sessions & 229 & Existence of training & I am not aware of it & 85.5 \\
\hline & $\begin{array}{l}\text { Always having crime-prevention } \\
\text { equipment on hand and ready to deploy }\end{array}$ & 102 & and drills & No answer & 5.5 \\
\hline & Review of staff uniforms & 47 & & I am aware of it & 29.0 \\
\hline & Lending of cell phones and alarm systems & 37 & Existence of a & I am not aware of it & 65.6 \\
\hline & Other & 132 & system & Cannot say either way & 0.1 \\
\hline & Proxy response to patients and their families & 459 & & No answer & 5.3 \\
\hline & Interviewing and counseling & 333 & & Yes & 7.3 \\
\hline $\begin{array}{l}\text { for staff } \\
\text { who have }\end{array}$ & $\begin{array}{l}\text { Cessation of contact with the patient or family } \\
\text { concerned }\end{array}$ & 193 & $\begin{array}{l}\text { Was the } \\
\text { post-incident }\end{array}$ & No & 8.7 \\
\hline experienced & Reassignment & 120 & $\begin{array}{l}\text { response within the } \\
\text { facility effective? }\end{array}$ & Cannot say either way & 80.1 \\
\hline & Allowing a leave of absence for a set time period & 20 & & No answer & 3.9 \\
\hline & Others & 76 & Could the & Yes & 26.5 \\
\hline & & & $\begin{array}{l}\text { experience be shared } \\
\text { in the workplace }\end{array}$ & No & 3.7 \\
\hline & & & after the incident? & Cannot say either way & 69.8 \\
\hline & & & & It was difficult to consult & 24.8 \\
\hline & & & & Did not know whom to ask & 22.9 \\
\hline & & & Reasons for not & $\begin{array}{l}\text { I did not think they would } \\
\text { understand how I felt }\end{array}$ & 20.0 \\
\hline & & & $\begin{array}{l}\text { being able to share } \\
\text { the experience in the }\end{array}$ & I handled it badly & 5.7 \\
\hline & & & workplace & $\begin{array}{l}\text { I let it go because it was a } \\
\text { child's doing }\end{array}$ & 3.8 \\
\hline & & & & I felt embarrassed & 2.9 \\
\hline & & & & Other & 19.9 \\
\hline
\end{tabular}

${ }^{\star}$ Rounded to the first decimal place. ${ }^{*}$ Multiple responses allowed.

higher among doctors [15]. A reason for the high percentage of physicians who reported experiencing some form of abuse in this survey may be that most of the facilities surveyed were clinics, where physicians have many opportunities to interact with patients and their families. They are also likely to be the providers of medical treatment that may not be in line with the wishes of patients and their families, a reason that was often cited as prompting incidents. As there was no 
considerable difference between the study's percentage of female doctors overall $(35.7 \%)$ and the percentage of female doctors who experienced victimization (32.4\%), the likelihood of a victimization experience in percentage terms among doctors was shown to be approximately the same for males and females in this study. Therefore, those most likely to experience victimization included physicians (of varying specialties) at a rate of less than $20 \%$ and nursing and administrative staff at a rate of less than $10 \%$.

The study found that, compared with better-equipped university hospitals and medical centers, clinics do not have adequate support systems to address the harm suffered by their staff. The security guards that are usually available and assigned at hospitals and medical centers are not available in clinics. Few security staff members responded to incidents (sometimes just one staff member); however, medical treatment and business operations tended to be immediately disrupted. In responses, "interruption of operations" was cited by the staff as having the most effect in terms of these incidents on their work. In pediatric departments, children do not visit the hospital alone; staff must deal with multiple attendants (i.e., parents or guardians) who may bring diverse ideas and values. The introduction of simulation materials with various hypothetical victimization scenarios that can be used by all staff members in medical settings is a necessary step [16] to address potential issues. Providing opportunities for discussions among staff members about these simulations are also important.

Of the 1103 total incidents reported in the study's survey, cases of verbal abuse were the most common, with 719 reports, followed by 248 cases of harassment. A survey of the distribution industry sector [17] also found that verbal abuse was the most common type of harassment, followed by complaints. Prior research has shown that demands for financial compensation and staff being subjected to demands for apologetic kneeling are unlikely to occur in public places such as supermarkets [17]. Similarly, this survey, which targeted outpatient clinics that are "easily visible to the public", reported no cases of monetary demands or of being forced to kneel in the waiting room. Typical situations included "anxiety over having to wait a long time for a medical examination for my sick child and frustration with inappropriate triage", "frustration and anger with the short consultation time compared to the long wait" and "frustration and anger with the staff's treatment of my child during the long wait".

While the "waiting time" before appointments or consultations has been reported to be the most common reason for verbal abuse and complaints by parents or guardians [17] [18], in this survey, "medical treatment and staff responses that are not in line with the wishes of the patient/family" was also frequently identified by staff as prompting incidents of victimization. In pediatric healthcare environments, there are cases where it is difficult to obtain informed consent from the patients themselves. There are also many cases where patients refuse to cooperate in the implementation of painful and distressing procedures. Given that most injuries due to violence resulted from the actions of child patients, it is suggested that, rather than explaining the procedure to the accompa- 
nying family members only or explaining the procedure to young children in the same way as to adults, the entire process should be explained appropriately to the child, including the sensations that the child is likely to experience during the procedure. Psychological preparation, using visual tools to help the child understand and accept the procedure, is required. However, due to the nature of pediatrics, it is also essential to provide explanations and support not only to patients but also to their families. In a busy outpatient clinic, interactions with patients and their families must be short. Suggestions for preliminary steps in preventing problems with patients and their families include conducting appropriately informative briefings to obtain informed consent or assent based on the age and developmental level of the child, managing detailed explanations and requests for family cooperation more effectively, and enabling highly flexible responses (including reporting, communication, and consultation) among staff.

As with previous surveys showing that the healthcare, nursing care, and welfare industries are among the most vulnerable to intimidation and threats among the various service industries [17], this survey found that employees working in medical facilities were particularly vulnerable to intimidation and threats from people accompanying patients, such as parents and extended family members. This study included "threats" that were classified as "verbal abuse". In addition to educating family members, being alert to malicious acts, and working to prevent malicious acts, relief care is urgently needed to address the mental health needs of staff members who experience victimization.

\subsection{Measures to Address Verbal Abuse, Physical Assault, and Harassment}

In this study, only approximately $10 \%$ of staff members were aware of the response manuals/guidelines and training/drills available at their facilities. The status of preparedness for countermeasures varied across facilities, depending on the number of hospital beds. Facilities with more than 300 beds had better response manuals and organizational care systems for affected staff than those with fewer than 300 beds [13]. The survey only asked if individual staff members were aware of countermeasures; therefore, it was not possible to determine if the countermeasures were genuinely available at the facilities nor was it possible to determine or confirm what was occurring in the actual environments. However, as clinics with zero beds accounted for a high percentage of the facilities surveyed, the possibility that manuals and training systems in such facilities are not sufficiently developed (and insufficiently circulated) needs to be considered.

The survey results revealed that fewer than $30 \%$ of affected employees felt able to share their experiences in the workplace. Some staff members indicated that it was difficult to discuss the issue concerned or that they did not know where to go for support. Some of the incidents of verbal abuse, physical assault, and harassment were so severe that the victim's self-respect appears to have been damaged. It is likely that there were cases where the victim was afraid to share information in the workplace because of the "embarrassment" of discussing the 
details of the incident. For all these reasons, it is necessary to establish a consultation and sharing system as well as a post-consultation care system in facilities. These systems should be led by facility managers, paying careful attention to protecting the privacy of victimized staff.

This study is the first to assess staff awareness of security measures implemented at their facilities, which included "installation of emergency call buttons and emergency phones" and "sharing of information on patients and families who have committed physical assault in the past". The study also identified that staff were aware of specific types of support for staff members who experienced harm, including "proxy response to the patients and families concerned" and "cessation of contact with the patients and families concerned". Staff members were found to be implementing measures cooperatively as a team. For example, evidence of malicious complainers or abusive people was recorded or videotaped and reported to the relevant facility manager. The support of external organizations, such as the police, was requested, and information was shared before refusing medical treatment to the patient or family member in question. Both patients/families and staff need to understand that malicious acts such as intimidation, threats, and violence are crimes. Education is essential for all parties; early staff training should be provided to help prevent aggression in healthcare settings.

Less than $10 \%$ of the staff rated the existing measures in their facilities as useful, whereas $45.6 \%$ of staff actually affected by an incident rated them as useful. This indicates that there were some staff members who utilized the measures and only recognized their usefulness after they were actually affected. Nevertheless, while $45.6 \%$ of the staff found the measures useful, less than half did not evaluate the measures as useful. Therefore, it is important to keep all staff members informed of existing hospital measures and to refresh their knowledge regularly. Specifically, posters (Supplementary material 1-4) should be displayed in conspicuous locations in outpatient clinics both to act as alerts and to prevent malicious behavior by patients and parents/guardians. All staff members should receive training using simulation materials that utilize various hypothetical victimization scenarios (Document 1). Staff should share knowledge, actively discuss relevant incidents and countermeasures, and help increase the versatility of contingency plans.

\subsection{Study Limitations and Future Research}

This study has several potential limitations. First, some cases of intimidation and threats were reported as harassment, while others were reported as verbal abuse. Similar experiences may have been reported differently depending on the perception of the staff member who responded to the survey. Second, in terms of offender characteristics, instances where the offender was an adult, and instances where the offender was a child were considered together and categorized as "patients" in the reporting survey and study results (Tables 3-5). Third, in recording the existence of security measures and manuals to deal with verbal abuse, vi- 
olence, and harassment occurring at facilities, the survey asked each staff member about the availability of these measures. However, the survey results serve only to gauge staff members' perceptions; there may be discrepancies with the actual measures available and implemented at the corresponding facilities. In terms of future research, the survey and study results will be utilized to develop and introduce simulation materials that can be used in pediatric healthcare settings in Japan.

\section{Conclusion}

This study surveyed experiences of verbal abuse, violence, and harassment perpetrated by patients and their families in pediatric healthcare settings as well as available countermeasures to such types of behavior. The findings indicated that approximately $10 \%$ of staff members had experienced some form of victimization in 2018. Some of the incidents involved acts that were malicious in nature, such as threats and intimidation. Approximately $10 \%$ of staff members were aware of the existence of manuals, guidelines, training, and drills related to these types of incidents at their facilities; $7.3 \%$ of the total respondents $(45.6 \%$ of the affected staff) deemed the existing measures in the facility to be useful. There is an urgent need to familiarize all pediatric medical facility staff with existing institutional countermeasures, as well as to review these countermeasures and implement measures that staff members perceive to be more effective.

\section{Acknowledgements}

We would like to express our sincere gratitude to the administrators and staff of the facilities who participated in this survey. We gratefully acknowledge the work of past and present members of our laboratory.

\section{Funding}

This research was funded by the Grant-in-Aid for Scientific Research from the Ministry of Education, Culture, Sports, Science, and Technology (MEXT), grant number $18 \mathrm{H} 03093$.

\section{Conflicts of Interest}

The authors declare that the research was conducted in the absence of any commercial or financial relationships that could be construed as a potential conflict of interest.

\section{References}

[1] Iwao, A., Fujiwara, K., Hasegawa, S., Ueno, K., Oota, H., Hasegawa, S., et al. (2013) The Actual State of In-Hospital Violence from Patients and Their Families Against the Staff of the Main Hospitals of Private Universities in Tokyo. Journal of the Japan Society for Healthcare Administration, 50, 219-227. (In Japanese) https://www.jstage.jst.go.jp/article/jsha/50/3/50_219/_article/-char/ja/

[2] Kaneko, T., Ishibashi, M. and Hibi, M. (2009) A Study on the Actual State of Ha- 
rassment by Patients and Related Countermeasures. The journal of Japan Society for Health Care Management, 10, 399-403. (In Japanese) https://www.jstage.jst.go.jp/article/jhm/10/2/10_399/_article/-char/ja/

[3] Gerberich, S., Church, T., McGovern, P., Hansen, H., Nachreiner, N., Geisser, M., et al. (2004) An Epidemiological Study of the Magnitude and Consequences of WorkRelated Violence: The Minnesota Nurses' Study. Occupational and Environmental Medicine, 61, 495-503. https://doi.org/10.1136/oem.2003.007294

[4] Shaw, J. (2015) Staff Perceptions of Workplace Violence in a Pediatric Emergency Department. Work, 51, 39-49. https://doi.org/10.3233/WOR-141895

[5] Li, Z., Yan, C., Shi, L., Mu, H., Li, X., Li, A., et al. (2017) Workplace Violence against Medical Staff of Chinese Children's Hospitals: A Cross-Sectional Study. PLoS ONE, 12, e0179373. https://doi.org/10.1371/journal.pone.0179373

[6] Derscheid, D. and Arnetz, J. (2020) Patient and Family Member Violent Situations in a Pediatric Hospital: A Descriptive Study. Journal of Pediatric Nursing, 55, 241-249. https://doi.org/10.1016/j.pedn.2020.07.014

[7] McAneney, C.M. and Shaw, K.N. (1994) Violence in the Pediatric Emergency Department. Annals of Emergency Medicine, 23, 1248-1251. https://doi.org/10.1016/S0196-0644(94)70349-3

[8] Partridge, B. and Affleck, J. (2017) Verbal Abuse and Physical Assault in the Emergency Department: Rates of Violence, Perceptions of Safety, and Attitudes towards Security. Australasian Emergency Nursing Journal, 20, 139-145. https://doi.org/10.1016/j.aenj.2017.05.001

[9] Nagai, H. (2009) Sociology of Helicopter Parent. Journal of the Faculty of Contemporary Society, Toyama University of International Studies, 1, 123-131. (In Japanese)

[10] Miki, A., Tomoda, H. and Ugaki, M. (2010) Actual State of Victimization and Response to Patient Violence by Role in Hospital Settings. Journal of Japanese Nursing Association: Psychiatric Nursing, 40, 42-44. (In Japanese)

[11] Tomoda, H., Miki, A., Ugaki, M. and Kawamoto, S. (2010) A Survey of Violence by Committed by Patients Against Hospital Workers: Comparison of Occupational Groups by Experience of Violence. Konan Women's University Researches, 4, 69-77. (In Japanese)

[12] Sugiura, M. (2010) A Survey of Verbal Abuse in Hospital and its Report in Johoku Hospital, Nagoya City University West Medical Center. Medical journal of Nagoya Municipal Hospital, 32, 11-14. (In Japanese)

[13] Amano, H., Kato, K., Miyaji, M., Fujiwara, N., Katsuyama, K., Kobayashi, S., et al. (2011) Abusive Language, Violence, and Sexual Harassment in Hospitals: a Survey of Hospitals in Aichi Prefecture, Japan. Journal of the Japan Society for Healthcare Administration, 48, 221-233. (In Japanese) https://www.jstage.jst.go.jp/article/jsha/48/4/48_4_221/_article/-char/ja/

[14] Miki, A., Suzuki, R., Nikaido, N., Atsumi, M., Serita, Y. and Kosuge, N. (2018) A Survey of Violence and Harassment by Patients and Their Families Experienced by Home Care Nurses and Others. Japan Journal of Nursing Science, 438, 725-731. (In Japanese)

[15] Oğuz, M., Sayın, E. and Gürses, D. (2020) Violence against Health Employees in a Child Health and Diseases Clinic: A Tertiary-Level Hospital Example. Turkish Archives of Pediatrics, 55, 117-123.

[16] Takamine, A. (2013) (Staff Education to Improve the Ability to Deal with Incidents of violence in Hospitals) Related Hospital-wide efforts! Development of Simulation Materials for Violence Prevention and Effectiveness of Study Sessions. Japan Jour- 
nal of Nursing Science, 38, 803-808. (In Japanese)

[17] National Textile Chemical Food Distribution Service General Labor Union Alliance (2020). UA Zensen Survey: Results of a Questionnaire Survey on Measures against Malicious Complaints and Nuisance. (In Japanese)

https://uazensen.jp/wp-content/uploads/2020/12/0caec75111f83bd517e16848d3799f $\underline{4 \text { d.pdf }}$

[18] Morita, H., Hagiwara, C. and Usami, M. (2012) A Survey of Complaint Content Perceived as a Stressor by Outpatient Nurses: Deriving Responses from Complaint Content. Journal of Japanese Nursing Association: Psychiatric Nursing, 42, 46-48. (In Japanese) 


\section{Supplementary Material 1-4}

\section{Document 1}
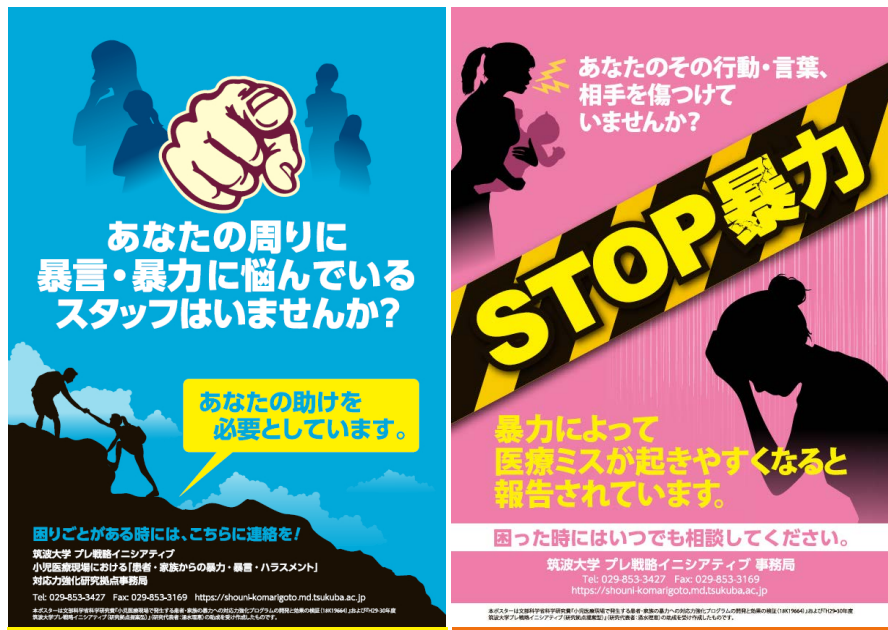

困った眭にはいつでも相談してください

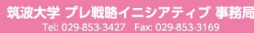

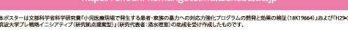

暴言・暴力や ハラスメント・嫌がらせに

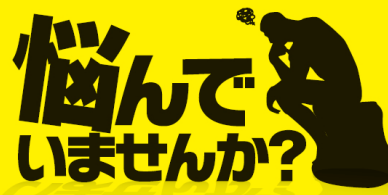

病院職員の半数以上の人が 暴力の被害にあっています

一人で悩まず、まずは相談を!

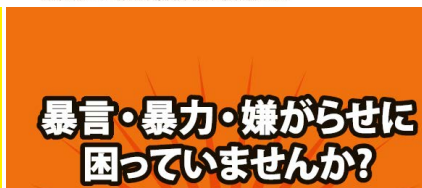

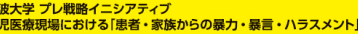

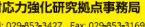

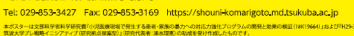

https://shouni-kazoku.jp/update/wp-content/uploads/2021/02/kensyu.pdf 